\title{
ESTRATÉGIAS EVOLUTIVAS PARA A REDE ÓPTICA A PARTIR DE ANÉIS WDM
}

\author{
J.R.P. Naves e H. Waldman
}

\begin{abstract}
Resumo - O aumento da planta de fibras em anéis WDM é uma possivel estratégia evolutiva para a rede óptica. Isto pode ser feito mantendo ou não a dimensionalidade dos nós e/ou a topologia do anel. Com a adição de mais fibra, podese simplcsmente duplicar o anel, ou então inserir nós roteadorcs, e obter configurações alternativas mediante a implementação de cordas sobre 0 anel, as quais são caracterizadas pelo número de lances (hops) subentendidos pela corda no anel original. Este artigo compara os ganhos de capacidade que podem ser obtidos através destas estratégias.
\end{abstract}

Palavras-Chave: WDM, anel óptico, alocação de rota e comprimento de onda, boqueio.

\begin{abstract}
Growing the fiber plant by adding up more WDM rings is a possible evolutionary strategy for the optical network. This can be done while keeping the nodal degrees or not. With the addition of more fiber, rings can be just duplicated with the addition of more OADM's and possible permutation of the nodes, or else they can be connected through routing nodes (OXC's). The latter altemative allows for the implementation of chords on the ring, which are characterized by the number of hops subtended by each chord in the original ring. This work compares the capacity gains that can be obtained through such strategies.
\end{abstract}

Keywords: WDM, optical ring, wavelenght and routing assignment, blocking.

\section{INTRODUÇÃO}

Pelo menos no ambiente das operadoras tradicionais de comunicações, a rede WDM surge normalmente da evolução de redes síncronas digitais ( $\mathrm{SDH} / \mathrm{SONET}$ ), que costumam assumir a topologia em anel para melhor provimento de facilidades de proteção ao seu elevado tráfego, que geralmente atende a um grande número de usuários. Rápidos avanços no desenvolvimento de componentes ópticos, tais como lasers e filtros sintonizáveis, bem como amplificadores e acopladores, têm permitido a transição a partir dos enlaces WDM ponto-aponto, para anéis WDM. A rede de caminhos ópticos está sendo viabilizada com o advento dos optical add-drop multiplexers (OADM's) e dos roteadores de comprimento

José Renato de Paula Naves é aluno de mestrado da UNICAMP, Helio Waldman é professor titular da UNICAMP. E-mails: jnaves@decom.fee.unicamp.br, waldman@decom.fee.unicamp.br. Este trabalho teve o apoio da FAPESP, da Ericsson e do CNPq.

Editores responsáveis: Antonio Sérgio Bezerra Sombra, Ricardo Menezes Campello de Souza e Max Gerken. Data de recebimento: 31/Dez/2001; data da revisão: 15/Mar/2002, data de aceitação: $8 / \mathrm{Abr} / 2002$. de onda (wavelength crossconects - OXC's). Um OADM pode seletivamente extrair ou adicionar um comprimento de onda específico entre os canais WDM transportados por uma fibra. Os outros comprimentos de onda passam opticamente pelo nó. Já um OXC provê a possibilidade de rotear canais individuais chegando em qualquer um dos seus portos de entrada, para qualquer um dos seus portos de saída. Desta forma, a configuração inicial em anel da rede WDM, tcm ainda a vantagem dc poder ser implementado apenas com OADM's, sem a necessidade de OXC's, cuja maior dimensionalidade (outdegree) exigc tecnologia mais sofisticada e cara.

Numa segunda fase evolutiva, porém, o crescimento do tráfego e, possivelmente, do número de nós, exige que o anel evolua. Vários recursos podem ser utilizados para ampliar a sua capacidade, como por exemplo, adicionar tecnologia aos nós, especialmente capacidade de converter - comprimento de onda de caminhos passantes (essa capacidade podc afetar parcialmente a transparência dos caminhos, e pode limitar a cascateabilidade dos nós na formação de caminhos, entre outras), duplicar o anel, inclusive os nós, alterando ou não a configuração e os recursos, como também, substituir os OADM's, total ou parcialmente, por OXC's de maior dimensionalidade, sendo plausível a adoção de OXC's com duas entradas e duas saídas, que preservam de certa forma a circularidade e direcionalidade da topologia fisica e da topologia de caminhos físicos (usando a nomenclatura de [1]). Esta opção implica na adição de mais fibra, porém segundo diversas alternativas topológicas.

A seção 2 descreve o modelo adotado para o anel WDM, os algoritmos de alocação de rota e comprimento de onda, bem como algumas métricas para umplementar um algoritmo de alocação de comprimento de onda no anel. A seção 3 apresenta diversas simulações para as estratégias de ampliação da capacidade da rede óptica, as quais são realizadas mediante a duplicação dos nós e mtrodução de nós roteadores. $\mathrm{Na}$ seção 4 , abordamos a proteção ao tráfego em redes ópticas, com vistas ao provimento de qualidade-de-serviço (QoS) destas à suas redes clientes, mais especificamente a internet. Por final, na seção 5 apresentamos algumas conclusões e sugestões para trabalhos futuros.

\section{MODELO PARA O ANEL WDM}

A comparação entre os desempenhos das topologias evolutivas deve tomar como referência algum modelo de atendimento ao tráfego. A literatura considera em geral dois casos extremos: a rede sem bloqueio, na qual se busca minimizar o número de comprimentos de onda da grade necessária para atender sem bloqueio todas as requisições de caminhos que respeitem o requisito de carga máxima sobre as fibras; e a rede com bloqueio, onde se busca 
minimizar a probabilidade de bloqueio para um dado tamanho da grade. O caso sem bloqueio é em geral mais difícil de ser analisado, pois é necessário identificar a seqüência de eventos de pior caso para o algoritmo de alocação de comprimento de onda em consideração. A natureza estatística da rede com bloqueio facilita o seu estudo pela via computacional, além disso, ela provavelmente se aproxima melhor de um modelo realista de atendimento. Por estes motivos, adotamos este modelo para as análises.

Seja $W$ o tamanho do conjunto (pool) de comprimentos de onda disponíveis para a alocação e $L \leq W$ a carga máxima das fibras, ou seja, o número máximo de comprimentos de onda permitidos em cada enlace. Supondo ausência de convertibilidade de comprimento de onda nos nós, $O$ anel fisico pode ser considerado como a união de $W$ sub-anéis disjuntos de um único comprimento de onda cada um, com a restrição de que cada enlace fica bloqueado se estiver sendo usado em $L$ sub-anéis.

A rede cliente (geralmente um anel SDH/SONET, no caso do anel óptico) gera requisições de conexões. Esta requisição irá gerar sucessivamente:

- Requisição de rota;

- Requisição de comprimento de onda na rota requisitada ou bloqueio da mesma. Neste caso, poderá ser requisitada outra rota que seja viável para a mesma conexão e reiniciada a busca de comprimento de onda. No caso do anel simples, só duas rotas são possíveis para cada conexão.

Uma requisição por um caminho ou rota será considerada ilegal se um ou mais dos enlaces requisitados estiver bloqueado. Entretanto, algumas requisições legais também poderão ser bloqueadas. Isto ocorrerá sempre que não houver nenhum comprimento de onda disponível simultaneamente em todos os enlaces requisitados, mesmo que todos eles tenham algum comprimento de onda disponível. A probabilidade disso ocorrer, entretanto, pode set minimizada pela adoção de um bom algoritmo de alocação de comprimento de onda [2]. Em geral, esses algoritmos estabelecem algum tipo de prioridade entre os comprimentos de onda, sendo por isso chamados de ajuste prionitário (first-fit).

Vários algoritmos de ajuste prioritário vêm sendo propostos na literatura, não havendo ainda consenso sobre qual seria o de melhor desempenho [3]. Por ordem de sofisticação e desempenho crescentes, consideramos os seguintes:

- Algoritmo Aleatório (AA), que simplesmente sorteia um comprimento de onda qualquer entre os disponíveis para a rota requisitada.

- Prioridade Fixa (PF). Esse algoritmo utiliza uma lista de comprimentos de onda estabelecida a priori. O primeiro da lista que não estiver bloqueado em nenhum enlace requisitado será alocado.

- MAXSUM (MS) [4]. Escolhe o comprimento de onda cuja alocação minimiza o número de rotas que passarão a ficar bloqueadas no comprimento de onda alocado.

Quando o algoritmo MS leva a um empate entre comprimentos de onda, o desempate é realizado por $\mathrm{PF}, \mathrm{o}$ qual, por construção nunca dá empatc.

\subsection{ALOCAÇÃO DE ROTA E COMPRIMENTO DE ONDA}

Em topologias genéricas a implementação do algoritmo MS é computacionalmente intensiva e depende do conhecimento da topologia da rede pelos nós de origem e destino da conexão. Em [5], mostrou-se que é possível implementar este algoritmo no anel óptico mediante o uso de métricas simples, que podem ser calculadas pelos nós de origem e destino.

Sejam, $\lambda_{l}, \lambda_{2}, \ldots, \lambda_{m}$ os $m$ comprimentos de onda disponíveis para acomodar a rota requisitada. Se o sub-anel correspondente ao comprimento de onda $\lambda_{i}$ já estiver acomodando pelo menos algum caminho preexistente, então a rota requisitada seria por ele acomodada num buraco $C_{i}$ (caminho disponível após uma alocação, ou cntre duas alocações no mesmo comprimento de onda) de tamanho $n_{i}=C_{i} \gtrless H$, onde $H$ é o número de enlaces da rota requisitada. A Figura 1 ilustra este cenário.

Figura 1. O conceito de buraco.



A acomodação no sub-anel $i$ substituirá o buraco $C_{i}$ por dois novos buracos, um à esquerda e outro à direita do novo caminho, de tamanhos $a_{i}$ e $b_{i}$ respectivamente, sendo:

$$
a_{i}+b_{i}+H=n_{i}
$$

Um buraco de tamanho $n$ é capaz de acomodar $n$ caminhos de 1 enlace, (n-1) caminhos de 2 enlaces, (n-2) de 3 enlaces,..., e 1 caminho de $n$ enlaces. O total de caminhos com os quais ele contribui com uma unidade de capacidade é, portanto:

$$
1+2+3+\ldots+n=\left(n^{2}+n\right) / 2 .
$$

Como a alocação de um buraco $C_{i}$ implicaria na substituição de um buraco de tamanho $n_{i}=\left|C_{i}\right|$ por dois de tamanho $a_{i}$ e $b_{i}$, o número de rotas disponíveis após a alocação será:

$$
\left(a^{2}+a\right) / 2+\left(b^{2}+b\right) / 2
$$

Desta forma, esta alocação retirará uma unidade de capacidade da seguinte quantidade de caminhos (a ser minimizada por MS):

$$
p_{i}=\frac{1}{2}\left(n_{i}^{2}-a_{i}^{2}-b_{i}^{2}+H\right)
$$

Supondo que estejamos coinparando comprimentos de onda numa única rota de tamanho $\mathrm{H}$, pode-se então adotar a seguinte métrica de comparação, a ser minimizada: 


$$
\mu_{i}=n_{i}^{2}-a_{i}^{2}-b_{i}^{2}=2\left(H n_{i}+a_{i} b_{i}\right)-H^{2},
$$

ou sua equivalente (para rota única):

$$
v_{i}=H n_{i}+a_{i} b_{i} .
$$

Contudo, se estivermos comparando comprimentos de onda sobre rotas diferentes, é necessário usar a métrica $p_{i}$ dada por (4), neste caso $H$ é função da rota, devendo portanto ser indexado juntamente com as demais variáveis.

A expressão da métrica $v_{i}$ em (6) evidencia que a alocação de comprimento de onda deve privilegiar, entre as opções de mesma rota: a) buracos de menor tamanho $n_{i}$; e b) buracos onde a inserção do novo eaminho seja mais assimétrica, o que minimiza o produto $a_{i} b_{i}$ para a mesma soma $a_{i}+b_{i}=n_{i}-H$. Como $a_{i} b_{i}$ é pelo menos zero e no máximo $\left(n_{r} H\right)^{2} / 4$, a condição para que a decisão seja tomada apenas com base no tamanho do buraco é que, para algum buraco, tenhamos:

$$
\begin{gathered}
H_{i} n_{i}+\frac{\left(n_{i}-H\right)^{2}}{4} \leq H\left(n_{i}+1\right) \\
\therefore n_{i} \leq H+2 \sqrt{H}
\end{gathered}
$$

Portanto, se (7) for satisfeita para algum buraco, pode-se afirmar que $o$ melhor comprimento de onda da rota (segundo MS) é o que apresenta o menor buraco para a inserção do caminho requisitado. $O$ uso dessas regras de decisão parece ser gerenciável pelos nós de origem e destino da rota, na medida em que tanto $a_{i}$ como $b_{i}$, e, portanto, $n_{i}$, podem ser obtidos por interrogação sucessiva dos nós adjacentes ao longo do anel.

Acoplando-se as regras de decisão de $\mathrm{AA}$ e/ou $\mathrm{PF}$ e/ou MS (obtidas anteriormente) a algoritmos de alocação de rota $[3,9]$, pode-se simular o desempenho destes para três níveis representativos de sofisticação em alocação de comprimento de onda. Para esse fim, são considerados os seguintes algoritmos de alocação de rota:

- Roteamento dinâmico com prioridade para o caminho mais curto (DRS - Dynamic Routing/Shortest Path First), no qual o caminho mais longo só é testado se for constatado boqueio da rota mais curta.

- Alocação conjunta de rota e comprimento de onda (JRW - Joint Routing and Wavelength Assignment).

Neste caso, o algoritmo deve comparar segundo algum critério todos os pares (rota, comprimento de onda) disponíveis, a fim de gerar uma escolha ou alocação.

Foram estudadas também algumas variações do algoritmo JRW, como por exemplo, a limitação no conjunto de rotas (com base no número de enlaces da menor rota) no qual deve ser feita a análise. As simulações utilizando o JRW foram feitas apenas para as redes com topologia em malha (formadas por OXC's e OADM's ou somente por OXC's), pois os critérios de escolha deste algoritmo podem ser melhor avaliados em razão do maior número de alternativas de roteamento em comparação com $\circ$ anel (o que torna possível o estudo de rotas com diversas granularidades).

\section{AMPLIAÇÃO DA PLANTA DE FIBRAS}

Nesta seção, é apresentado o desempenho simulado de algumas possíveis topologias evolutivas a partir do anel, através da ampliação da planta de fibras. O desempenho é caracterizado pela probabilidade de bloqueio como função do nível de tráfego por nó. Em todas as simulações, o regime estatístico de tráfego é caracterizado por chegadas poissonianas de requisições e retenção exponencial dos caminhos, ou seja, tráfego sem memória. Com relação a distribuição espaeial do tráfego, considera-se $o$ caso onde $o$ tráfego é uniforme, ou seja, todos os pares origem-destino têm a mesma probabilidade de gerar uma requisição de caminho.

\subsection{DUPLICAÇÃo DOS NÓS}

Supondo que um anel com 16 nós e 4 comprimentos de onda, seja simplesmente duplicado, ou seja, construido um novo anel com mais 16 OADM's e 4 comprimentos de onda, o aumento de capacidade resultante depende da forma como os dois anéis forem gerenciados para atender tráfego agregado [6]. Nas simulações apresentadas a seguir, considera-se o gerenciamento conjunto dos recursos, ou seja, a alocação é feita por um gerenciador comum aos dois anéis, que aplica o algoritmo de alocação de comprimento de onda sobre os $2 \mathrm{~L}$ pares [fibra, comprimento de onda] (sendo L a carga máxima das fibras). Tomou-se como referência o algoritmo MS, já que em estudos preliminares verificoul-se que ele proporciona ao anel de caminhos ópticos uma maior capacidade de atendimento ao tráfego em comparação com os demais algoritmos, e para o roteamento dos comprimentos de onda foi utilizado o algoritmo DRS.

A Figura 2 mostra a simulação realizada no anel duplo, na qual compara-se o efeito de tentar atender a uma requisição, somente utilizando as duas rotas mais curtas (no caso da não disponibilidade de comprimentos de onda nestas rotas a requisição é bloqueada), e quando dispõe-se de todas as rotas possíveis (são 4) para atender a requisição. Esta figura também compara os ganhos obtidos a partir da duplicação dos nós, com o anel simples (sem duplicação).

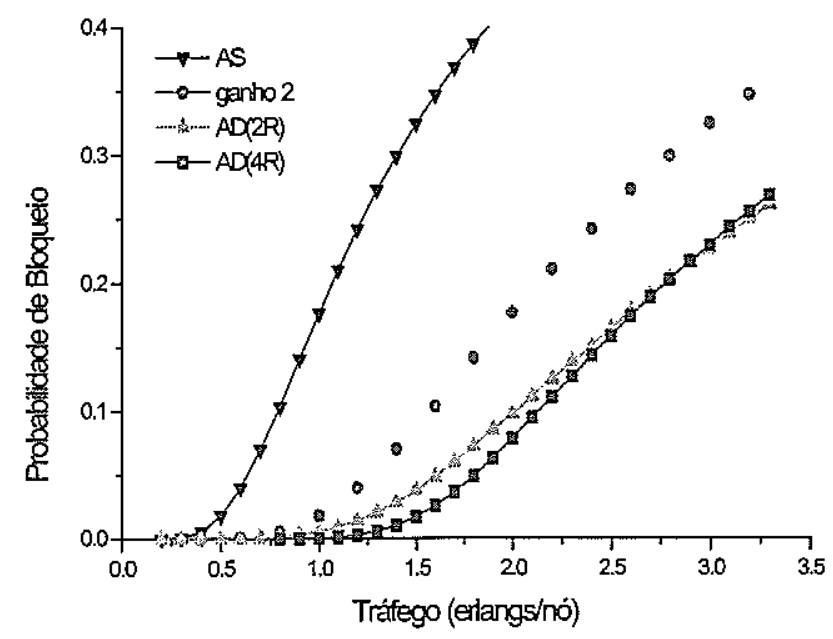

Figura 2. Comparação do desempenho do algoritmo MS no anel simples (AS) e no anel duplo (AD) para 2 e 4 rotas. 
A duplicação do anel com a integração do seu gerenciamento, produziu ganhos de entroncamento, ou seja, o tráfego que era anteriormente atendido no anel simples foi mais que duplicado, para uma mesma probabilidade de bloqueio (a curva "ganho 2" na figura anterior representa o dobro do tráfego do anel simples). Observa-se também que para níveis de tráfego mais baixos, tentar atender a uma requisição utilizando todas as possibilidades de rotas, é mais vantajoso que só utilizar as duas rotas mais curtas, entretanto, para um determinado nível crítico de tráfego esta situação inverte-se. Para as simulações seguintes, são consideradas todas as possibilidades de rotas.

No caso anterior, os dois anéis possuíam a mesma configuração de conexões, ou seja, o nó 0 (zero) conectado com o nó 1 , o nó 1 com o 2, o 2 com o 3, e assim por diante, ou seja, o segundo anel foi construído com cordas de tamanho $1(a=1)$, em relação ao anel original. A Figura 3 ilustra as topologias resultantes quando utilizam-se cordas de tamanho 2 e 3 .

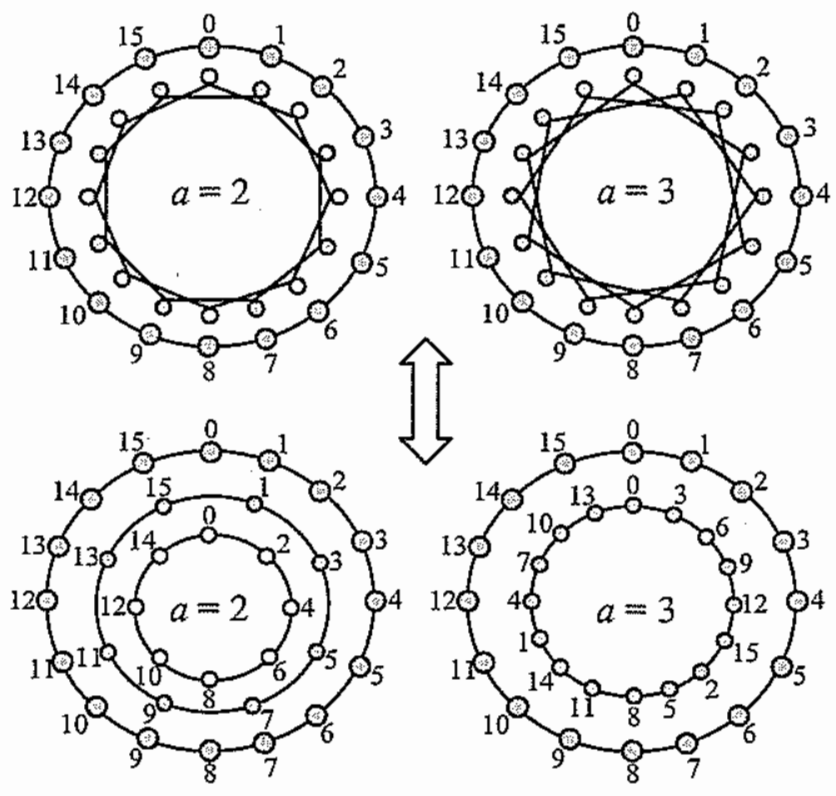

Figura 3. Duplicação dos nós para $a=2$ e 3 .

Para o caso $a=2$, é importante observar que os anéis de cordas não oferecem conectividade total, não sendo possível atender as requisições entre nós pares e nós ímpares, desta forma, esta topologia só oferecerá 2 alternativas de roteamento para estas requisições (só poderão ser atendidas pelo anel original). Já para $a=3$, para todas as possibilidades de requisições são disponibilizadas 4 alternativas de rotas.

A Figura 4, mostra uma comparação entre os desempenhos destas topologias, bem como para o caso da duplicação do anel sem alteração da configuração dos nós $(a=1)$ (apresentado anteriormente).

Como pode-se observar por esta figura, o anel duplo com $a=3$, apresenta o melhor desempenho. Comparando-se as topologias $a=1$ com $a=2$, observa-se que para níveis de tráfego abaixo de 2,3 erlangs/nó, o anel duplo com $a=1$ proporeiona uma maior capacidade de atendimento ao tráfego, já para valores superiores, o anel com $a=2$ é a melhor escolha. É importante observar que neste último, a rota mais curta é sempre menor ou igual ao caso $a=1$, além disso, quando são possíveis as 4 rotas, as 2 disponibilizadas pelo anel de cordas serão menores do que no caso $a=1$.

Portanto, quando o nível de tráfego é alto, a alocação de uma requisição em rotas mais curtas, diminui a probabilidade de bloqueio média da rede. $O$ fato de sempre dispor-se de 4 alternativas de roteamento para uma dada requisição $(a=1)$, mesmo que para isso utilize-se rotas longas, só é vantajoso quando o tráfego é baixo.

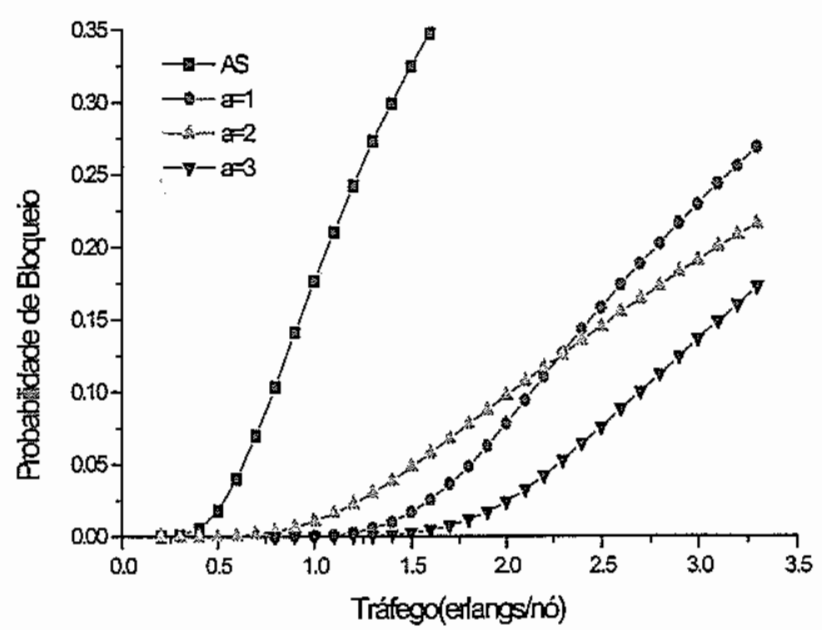

Figura 4. Resultados das simulações no anel simples e nos anéis duplos com $a=1, a=2$ e $a=3$.

No caso da topologia $a=3$, verifica-se que a rota mais curta é sempre menor ou igual ao caso $a=1$. Observa-se também que quando utiliza-se cordas de tamanho 3 , aumenta-se as possibilidades de atendimento de uma requisição com um único hop, já que, aumenta-se a "vizinhança" de cada nó. Por exemplo, o nó 0 possui como vizinhos os nós $1,15,3$ e 13, e para corda 1 , somente os nós 1 e 15. Para os outros valores de cordas que oferecem conectividade total para o novo anel (ou seja, cordas que não são múltiplos de 16 ), o resultado é o mesmo que no caso $a=3$, pois a única diferença é na configuração das conexões, e como o tráfego é espacialmente uniforme, elas têm a mesma probabilidade de oconrer.



Figura 5. Resultados das simulações nos anéis simples e duplo com 17 nós, para cordas de tamanhos $1,2,3$ e 4 . 
A Figura 5 apresenta as simulações realizadas em anéis com um número primo de nós (17). O objetivo é verificar o desempenho destes para as cordas de tamanho 1, 2, 3 e 4 já que neste caso a corda de tamanho 2 também proporcionará conectividade total ao novo anel.

Como era de se esperar, quando o número de nós é primo, a diferença de desempenho entre as topologias com cordas 2 e 3 é bastante pequena, mas ainda assim, o anel duplo com $a=3$ possibilita uma maior capacidade. Devido a distribuição uniforme do tráfego, as topologias com cordas maiores apresentaram desempenho praticamente igual ao caso $a=3$ (na figura é mostrado somente a topologia $a=4$ ). Esta pequena diferença entre a corda 2 e as demais (maiores que 2), deve-se ao fato de que nestas últimas, em média, as requisições são atendidas com rotas menores, em função de uma melhor distribuição das configurações de conexões nos anéis em comparação com o caso $a=2$, no qual, a diferença de tamanho das conexões lógicas entre os dois anéis é de apenas 1 hop.

Na seção seguinte é apresentado uma outra estratégia de ampliação da capacidade do anel, a qual utiliza nós roteadores.

\subsection{NÓS ROTEADORES (OXC'S)}

Quando a duplicação das fibras se dá em torno de nós roteadores, novas alternativas de caminhos fisicos são geradas. A duplicação de fibras em torno de nós roteadores é equivalente a uma situação em que:

- Duplicássemos o número de comprimentos de onda; e

- Introduzíssemos uma convertibilidade parcial de comprimentos de onda de grau 2 , na qual os comprimentos de onda são divididos em pares em cujo interior a convertibilidade é plena.

A aplicação do algoritmo MS no anel duplicado com nós roteadores exige alguma discussão. A rigor, uma requisição que passe por $\mathrm{H}$ enlaces disporia de $2^{\mathrm{H}}$ rotas pelo caminho mais curto, de maneira que o problema de alocação de rota ressurge aparentemente. $\mathrm{Na}$ verdade, porém, esse problema é apenas aparente, pois a passagem de um caminho por qualquer uma das duas fibras, quando ambas são disponíveis, é totalmente indiferente. Assim sendo, pode-se entender por "rota", para efeito da aplicação do algoritmo MS, ao conjunto dos enlaces oferecidos pelas duas fibras entre dois nós.

A Figura 6 ilustra possíveis topologias evolutivas a partir do anel, formadas por OADM's e OXC's. Como o modelo de tráfego adotado é espacialmente uniforme, a disposição dos recursos foi estabelecida de forma a nuanter ao máximo a simetria da rede. Nestas topologias, o anel periférico e as cordas são bidirecionais formados por 1 par de fibras, das quais, uma é usada para dar suporte ao tráfego no sentido horário e a outra no sentido anti-horário. Em todas as simulações consideramos que a carga máxima suportada pelas fibras e o número de comprimentos são iguais a 4 .

O programa elaborado inicialmente determina todas as rotas possiveis entre cada par origem-destino. É importante esclarecer que entende-se por rotas possíveis aquelas que partindo do nó origem, chegam ao nó destino sem fazer loops, ou seja, a rota não passa duas vezes pelo mesmo nó, assim, as rotas terão um tamanho mínimo de 1 enlace e tamanho máximo de 15 enlaces.

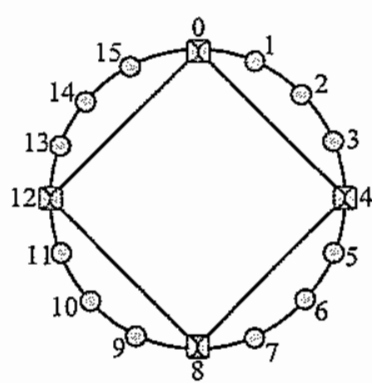

a)

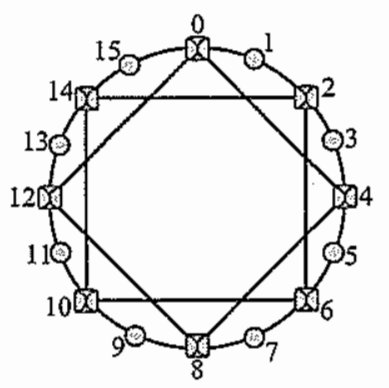

c)

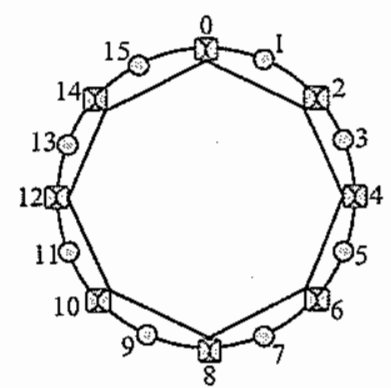

b)
OADM'S

OXX $\mathrm{OXC}$

Figura 6. Ampliação da planta de fibras no anel usando OXC's. (a) Anel Cordas a $=4(4 O X C$ 's). Rede formada por $25 \%$ dos nós sendo OXC's. (b) Anel Cordas a $=2$ (8OXC'). (c) Anel Cordas $a=4\left(8 O X C^{\prime} s\right)$. As redes das figuras b) e c) são constituídas por $50 \%$ dos nós sendo OXC's e os outros $50 \%$ OADM's.

Na Tabela 1 é mostrado como a utilização de OXC's proporciona um aumento no número de alternativas de roteamento em comparação com as topologias anulares, formadas somente por OADM's (2 rotas possiveis no caso do anel simples e 4 no caso do anel duplo).

\begin{tabular}{|l|l|l|}
\hline Topologias & Total & Média \\
\hline$a=4$ (4OXC's) & 3.136 & 13,07 \\
\hline$a=2$ (8OXC's) & 23.392 & 97,47 \\
\hline$a=4$ (8OXC's) & 24.736 & 103,07 \\
\hline
\end{tabular}

Tabela 1. Número de rotas para as redes apresentadas na Figura 5.

Nesta tabela, a coluna "Total" indica o número total de rotas para as topologias apresentadas na Figura 6, e a coluna "Média" mostra o número médio de rotas por par origemdestino (o número de pares origem-destino é igual a 240 (16x15)).

A Figura 7 mostra uma comparação entre os desempenhos das topologias anteriores, bem como para o caso da duplicação dos nós com $a=1$ e $a=3$. Em todos os casos o algoritmo de roteamento utilizado foi o DRS.

Observa-se que as redes com 8 OXC's proporcionam uma maior capacidade de atendimento ao tráfego em comparação com a que utiliza 4 OXC's. Em comparação com a duplicação dos nós, verifica-se que somente a rede Anel Cordas a $=4$ (8OXC's) foi superior a topologia $a=1$ e superior a topologia $a=3$ para valores de tráfego inferiores a 
2,5 erlangs/nó. Para níveis de tráfego mais altos esta situação inverte-se.

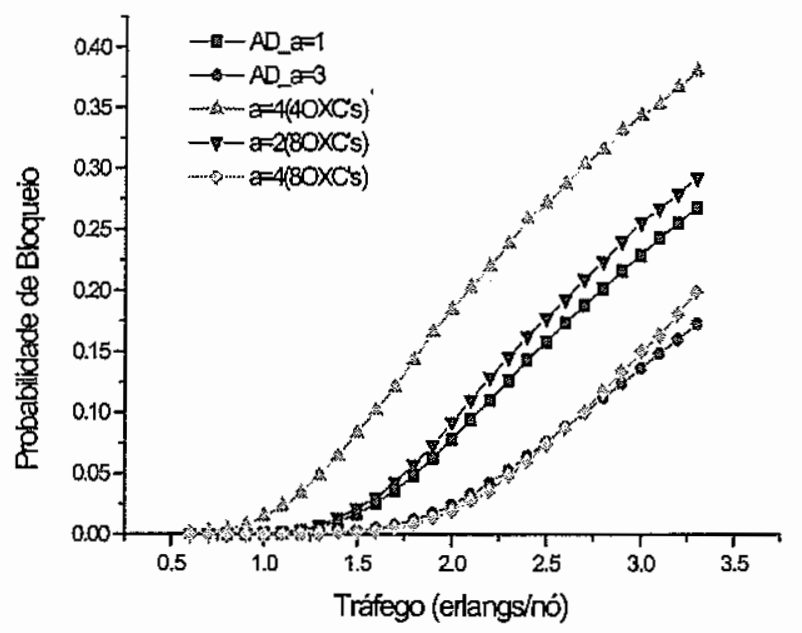

Figura 7. Comparação dos ganhos de capacidade provenientes da duplicação dos nós e da introdução de nós roteadores.

Supondo que os custos dominantes sejam dados pelos OXC's, os investimentos de hardware nas redes Anel Cordas $a=2(80 X C$ 's) e Anel Cordas $a=4(8$ OXC's) são aproximadamente iguais. Entretanto, esta última apresentou um desempenho bastante superior a primeira. Neste caso, além da rede Anel Cordas a $=4$ (8OXC's) disponibilizar um número maior de rotas, verifica-se a mesma situação da duplicação dos nós com $a=2$ e $a=3$ (ou maior), pois devido a natureza espacialmente uniforme do tráfego, a rede Anel Cordas $a=4(8 \mathrm{OXC}$ 's) por possuir uma corda maior que a rede Anel Cordas $a=2(80 \mathrm{XC}$ 's), em média, atenderá às requisições com rotas menores, pois as requisições entre nós vizinhos pode ser atendida pelo anel periférico, enquanto que para as requisições mais longas, esta corda possibilita trajetos menores em comparação com a rede de corda 2, pois a diferença nesta última, em número de enlaces, da corda para o anel periférico é apenas 1. Desta forma, pode-se concluir que o atendimento das requisições em rotas curtas diminui a probabilidade de bloqueio média da rede.

\subsubsection{ALOCAÇÃO CONJUNTA DE ROTA E COMPRIMENTO DE ONDA}

Com o intuito de buscar alternativas de roteamento que aumentem a capacidade de atendimento ao tráfego das redes ópticas, nos pareceu bastante interessante o estudo de um algoritmo de alocação conjunta de rota e comprimento de onda. Adotamos como critério para a escolha do par (rota, comprimento de onda) o algoritino MS, desta forma, o JRW deverá encontrar a rota e o comprimento de onda que minimizam a perda de capacidade para a rede, ou seja, o número de rotas que passarão a ficar bloqueadas após uma dada alocação. É importante observar que o algoritmo MS é um algoritmo de alocação de comprimento de onda, o que estamos fazendo é uma adaptação para que o mesmo seja aplicado também na escollha das rotas.

A Figura 8 mostra as simulações realizadas nas redes Anel Cordas $a=4(40 X C ' s)$ e Anèl Cordas $a=4(80 X C ' s)$, onde são feitas comparações entre os algoritmos JRW e DRS.



Figura 8. Comparação entre algoritmos de roteamento para as topologias apresentadas nas figuras $5 a$ ) e $5 c$ ).

Nota-se claramente que o desempenho do algoritmo JRW foi inferior ao DRS, principalmente no caso da rede Anel Cordas $a=4\left(80 \mathrm{XC}^{\prime} \mathrm{s}\right)$.

Como os nós da rede não têm capacidade de conversão, cada comprimento de onda pode ser considerado como uma sub-rede distinta, desta forma, a menor rota para um dado par origem-destino pode variar de um comprimento de onda para o outro. Dependendo do estado da rede, a menor rota entre os comprimentos de onda, pode causar uma perda de capacidade maior (geralmente quando não há nenhuma requisição alocada neste comprimento de onda) que uma rota maior em outro comprimento de onda (em função deste já abrigar outras requisições). Este fato também foi observado para as requisições dentro de um mesmo comprimento de onda, ou seja, nem sempre a menor rota para um par origem-destino causa a menor perda de capacidade.

A Tabela 2 foi obtida a partir da rede Anel Cordas $a=4(80 X C$ 's), observando-se passo a passo 0 funcionamento do algoritno JRW . Nesta tabela, o campo "№ R.A." mostra o número de rotas disponíveis em cada comprimento de onda antes da próxima alocação. Os campos "Rota" e "P.Cap." indicam as rotas determinadas pelo JRW e suas respectivas perdas de capacidade (em número de rotas) caso a rota seja alocada. Os campos em negrito nesta tabela, indicam os parâmetros escolhidos pelo algoritmo $(\lambda$, rota).

Como o critério de desempate para o MS é a prioridade fixa, na primeira requisição é alocado o comprimento de onda $\lambda_{0}$. Para as duas requisições seguintes, a menor rota entre os pares origem-destino é a mesma para $\lambda_{0}$ e $\lambda_{1}$, entretanto, como $\lambda_{0}$ já abriga uma requisição a perda de capacidade neste comprimento de onda será menor que em $\lambda_{1}, \operatorname{logo}$, este será o comprimento de onda alocado. Como pode-se observar, nas requisições entre os nós $13 \rightarrow 5 \mathrm{e}$ $15 \rightarrow 0, \lambda_{1}$ possibilita as menores rotas, entretanto, o algoritmo opta por alocar as requisições em $\lambda_{0}$, pois a perda de capacidade será menor que em $\lambda_{1}$, embora as rotas sejam maiores neste comprimento de onda. Nota-se ainda que na 
requisição $13 \rightarrow 5$, o algoritmo determinou que em $\lambda_{0}$, a rota $13 \rightarrow 14 \rightarrow 2 \rightarrow 3 \rightarrow 4 \rightarrow 5$ é "melhor", por exemplo, que a rota $13 \rightarrow 12 \rightarrow 0 \rightarrow 4 \rightarrow 5$. Futuramente estes procedimentos irão causar prejuízos no que diz respeito a probabilidade de bloqueio média desta rede, pois dependendo do tempo que estas conexões fiquem ativas, elas provavelmente bloquearão um número maior de requisições em comparação com aquele que seria bloqueado se as menores rotas fossem alocadas. Assim, o algoritmo de alocação conjunta de rota e comprimento de onda, aplicado segundo o MS, diferentemente do que podia-se imaginar, não leva a uma otimização na probabilidade de bloqueio da rede, sendo seu desempenho inferior à alocação separada de rota e comprimento de onda.

\begin{tabular}{|c|c|c|c|c|c|}
\hline No & ND & $\lambda$ & $\mathbf{N}^{\circ} \mathbf{R} \cdot \mathbf{A}$ & P.Cap & Rota \\
\hline \multirow[t]{2}{*}{11} & 5 & 0 & 24.736 & 10.133 & $11-10-6-5$ \\
\hline & & 1 & 24.736 & 10.133 & $11-10-6-5$ \\
\hline \multirow[t]{2}{*}{4} & 10 & 0 & 14.603 & 4.791 & $4-8-9-10$ \\
\hline & & 1 & 24.736 & 8.423 & $4-8-9-10$ \\
\hline \multirow[t]{2}{*}{1} & 8 & 0 & 9.812 & 4.081 & $1-0-12-8$ \\
\hline & & 1 & 24.736 & 10.178 & $1-0-12-8$ \\
\hline \multirow[t]{2}{*}{13} & 5 & 0 & 5.731 & 3.351 & $13-14-2-3-4-5$ \\
\hline & & 1 & 24.736 & 12.761 & $13-14-10-6-5$ \\
\hline \multirow[t]{2}{*}{15} & 4 & 0 & 2.380 & 653 & $15-0-4$ \\
\hline & & 1 & 24.736 & 7.680 & $15-0-4$ \\
\hline \multirow[t]{2}{*}{15} & 0 & 0 & 1.727 & 1.008 & $15-14-13-12-0$ \\
\hline & & 1 & 24.736 & 4.620 & $15-0$ \\
\hline \multirow[t]{2}{*}{15} & 7 & 0 & $-\cdots$ & - & - \\
\hline & & 1 & 24.736 & 12.761 & $15-0-4-8-7$ \\
\hline \multirow[t]{2}{*}{13} & 9 & 0 & |----- & --..--. & (-..... \\
\hline & & 1 & 11.975 & 4.884 & $13-12-8-9$ \\
\hline
\end{tabular}

Tabela 2. Rotas que causam a menor perda de capacidade para cada comprimento de onda. O algoritmo deve decidir dentre estes pares qual deve ser escolhido.

Deste modo, foi feito uma modificação no algoritmo $\mathrm{JRW}$, para que a escolha da rota fosse feita somente entre as menores disponíveis para uma dada requisição, ou seja, o algoritmo determina a menor rota dentre todos os comprimentos de onda, estabelecendo assim um limitante, a partir do qual só poderão ser analisadas rotas de mesmo tamanho (em número de enlaces). Passaremos a chamar este algoritmo de JRW_SP (Joint Routing and Wavelength Shortest Path).

Na Figura 9 é feita uma comparação entre os algoritmos JRW, JRW_SP e DRS, para as topologias Anel Cordas $a=4\left(40 X C^{\prime}\right.$ 's) e Anel Cordas $a=4(80 X C$ 's).

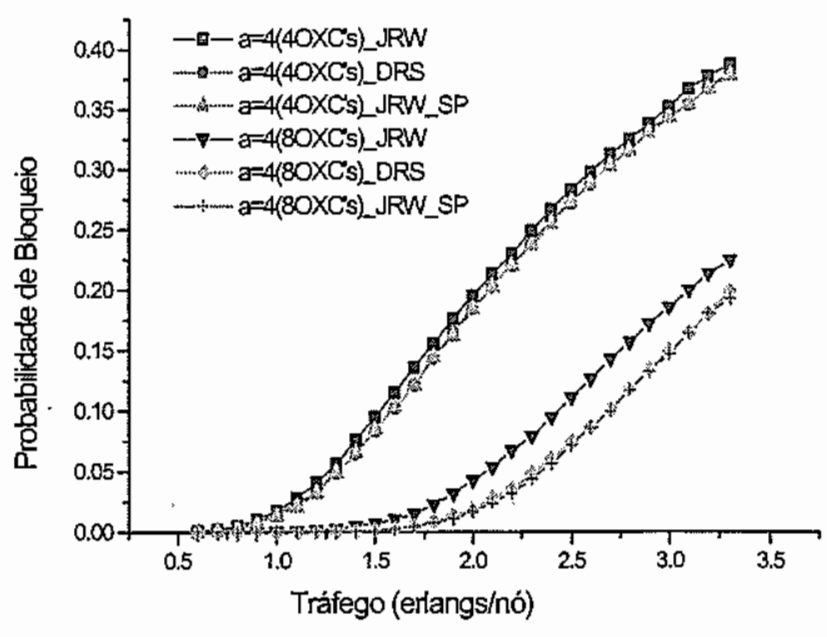

Figura 9. Comparação entre os desempenhos dos algoritmos JRW, DRS e JRW_SP.

Como pode-se notar pela figura anterior, o desempenho do algoritmo JRW_SP foi praticamente o mesmo que o DRS, podendo-se notar um pequena superioridade do primeiro para a rede Anel Cordas $a=4(80 X C ' s)$. É de se esperar que para redes mais emaranhadas, ou seja, com mais alternativas de roteamento entre cada par de nós, a diferença de desempenho entre estes dois algoritmos possa ser maior, visto que haverá uma maior quantidade de menores rotas a serem analisadas, devendo haver portanto dentre estas rotas diferenças mais significativas (com relação a perda de capacidade que cada uma causa), o que no caso do DRS levaria a uma perda de desempenho, já que este escolhe uma rota qualquer dentre as menores para em seguida ser feita a alocação de comprimento de onda.

Em todas as simulações seguintes foi usado o algoritmo JRW_SP como referência, para efeito de comparação com outros algoritmos de roteamento.

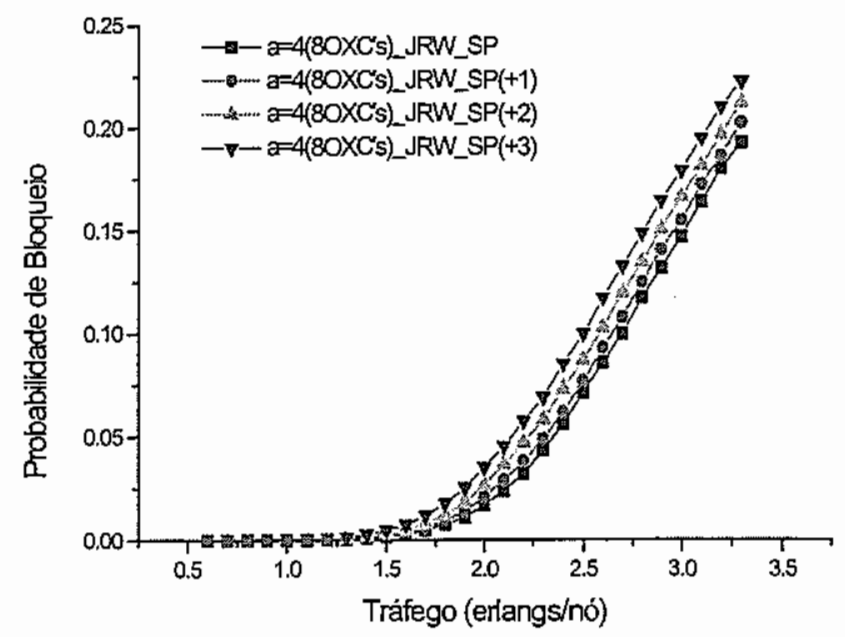

Figura 10. Comparação entre os desempenhos dos algoritmos com limitação no tamanho das rotas disponíveis.

Para verificar até que ponto a escolha de uma rota que não seja a menor é prejudicial ao desempenho da rede, alteramos o algoritmo JRW_SP para que o mesmo fizesse a seleção da rota não somente entre as menores disponíveis, 
mas entre as menores +1 enlace, $+2 e+3$ enlaces. Passamos a chamar estes algoritmos de JRW_SP(+1), JRW_SP(+2) e JRW_SP(+3), respectivamente. As simulações realizadas na rede Anel Cordas $a=4$ (8OXC's) estão apresentadas na Figura 10.

Observa-se que o melhor desempenho é obtido para o algoritmo JRW_SP. Portanto, permitir alocar uma requisição com 1 enlace a mais do que a menor rota já aumenta a probabilidade de bloqueio média da rede, e continua aumentando para rotas mais longas.

Como uma última variação do algoritmo $\mathrm{JRW}$, estamos imteressados agora na alocação de rota e comprimento de onda com base na perda relativa de rotas. Voltando a Tabela 2 , observa-se que quando da requisição $15 \rightarrow 0$, o algoritmo JRW escolheu a rota $15 \rightarrow 14 \rightarrow 13 \rightarrow 12 \rightarrow 0$ no comprimento de onda $\lambda_{0}$, já que este par causava uma menor perda de capacidade em comparação com a rota $15 \rightarrow 0$ em $\lambda_{1}$. Entretanto, analisando este fato com mais cuidado verifica-se que a rota em $\lambda_{0}$ provocou uma perda de 1.008 rotas dentre as 1.727 disponíveis antes da alocação, enquanto que em $\lambda_{1}$ a perda foi de 4.620 entre 24.736 . Portanto, a perda relativa de rotas em $\lambda_{1}$ é menor que em $\lambda_{0}$ $\left(\mathrm{P}_{\text {rel }}\left(\lambda_{1}\right)=4.620 / 24.736=0,186\right.$ e $\left.\mathrm{P}_{\mathrm{rel}}\left(\lambda_{0}\right)=1.008 / 1.727=0,58\right)$.

A Figura 11 mostra as simulações na rede Anel Cordas $a=4$ (8OXC's), sendo que o algoritmo JRW_RL (Joint Routing and Wavelength Relative Loss) adota como critério de seleção de rota e comprimento de onda, a menor perda relativa de capacidade.



Figura 11. Comparação entre os desempenhos dos algoritmos considerando a perda global de capacidade e perda relativa de capacidade.

Como pode-se observar por esta figura, o desempenho do algoritmo JRW_RL foi inferior ao JRW_SP e superior ao JRW, os quais analisam a perda global de capacidade. $O$ critério usado pelo JRW_RL não permite que rotas longas sejam preferidas às curtas, que é justamente o mesmo o critério empregado pelo JRW_SP. Assim, a diferença básica entre estes dois algoritmos está na escolha do comprimento de onda. Para ilustrar, podemos usar como exemplo as requisições entre os nós $1 \rightarrow 8$ e $15 \rightarrow 4$ (Tabela 2), em ambos os comprimentos de onda a rota é a mesma, para o JRW_SP o comprimento de onda escolhido é $\lambda_{0}$ nos dois casos (pois é o que provoca a menor perda global de capacidade), ao passo que, segundo o critério do JRW_RL os comprimentos de onda selecionados seriam $\lambda_{1}$ e $\lambda_{0}\left(1^{0}\right.$ caso: $P_{\text {rel }}\left(\lambda_{1}\right)=0,411$ e $P_{\text {ret }}\left(\lambda_{0}\right)=0,416,2^{\underline{o}}$ caso: $\mathrm{P}_{\text {rel }}\left(\lambda_{0}\right)=0,274$ e $\left.\mathrm{P}_{\text {rel }}\left(\lambda_{1}\right)=0,31\right)$. Deste modo, no que diz respeito a alocação de comprimento de onda, o algoritmo JRW_RL perde a característica básica do MS, o qual, por ser do tipo first-fit, procura sempre que possível usar o mesmo comprimento de onda, com o objetivo de deixar livres os demais, preservando a probabilidade de bloqueio instantânea da rede quando ela é 0 (zero). E, como se sabe, este tipo de algoritmo é melhor do que aqueles que buscam fazer o balanceamento da carga na rede.

$\mathrm{Na}$ seção seguinte são apresentadas as simulações realizadas em redes óptieas formadas somente por $\mathrm{OXC}^{\prime} \mathrm{s}$ originadas a partir da implementação de cordas sobre um um anel com 16 nós. Passaremos a chamar estas redes de "Anel Malha".

\subsubsection{ANEL MALHA}

Os OXC's configurados para operar em topologias emaranhadas oferecem uma grande flexibilidade e tornam melhor o uso da capacidade disponível das redes ópticas. Nos estudos realizados nesta topologia consideramos que todos os nós da rede tem grau de conexão 4, ou seja, cada nó pode se conectar a outros 4 .

Diversas configurações podem ser obtidas mediante a utilização de cordas de diferentes tamanhos. Na Figura 12 é apresentada uma rede constituída por cordas de tamanho 3 . Neste tipo de rede o número de alternativas de roteamento assume valores bastante elevados $\mathrm{e}$ pode variar sensivelmente dependendo do valor adotado para a corda.

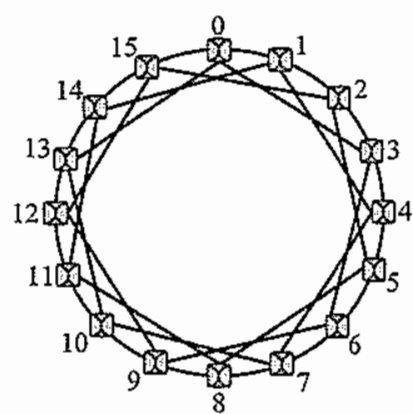

Figura 12. Anel Malha formado somente por OXC's e a=3.

$\mathrm{Na}$ Tabela 3, são mostrados o número total de rotas da rede e o número de rotas de cada nó, para $a=2,3, \ldots, 7$.

\begin{tabular}{|l|l|l|}
\hline Corda (a) & № Total de Rotas & № de Rotas por Nó \\
\hline 2 & 1.173 .216 & 73.326 \\
\hline 3 & 1.424 .384 & 89.024 \\
\hline 4 & 1.480 .928 & 92.558 \\
\hline 5 & 1.424 .384 & 89.024 \\
\hline 6 & 1.512 .192 & 94.512 \\
\hline 7 & 1.404 .096 & 87.756 \\
\hline
\end{tabular}

Tabela 3. Variação do número de rotas em função do tamanho da corda. 
Como estas topologias são simétricas, o número de rotas de um nó para os demais é o mesmo para cada nó dentro de cada topologia (cada valor de corda).

$\mathrm{Na}$ Figura 13 são mostradas as simulações realizadas para as topologias descritas na Tabela $3(\mathrm{~N}=16$ e W=4) usando como algoritmo de alocação de rota e comprimento de onda o JRW_SP.

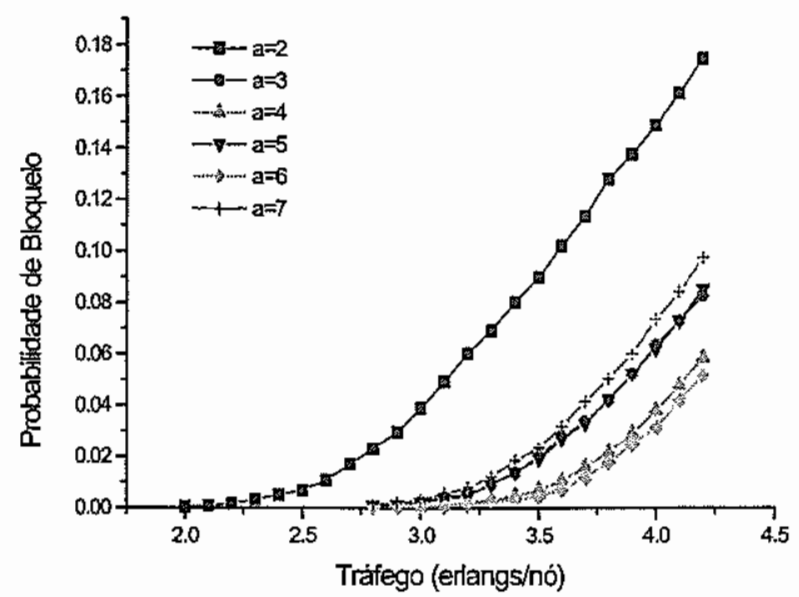

Figura 13. Comparação entre as topologias Anel Malha, para $a=2, . ., 7$.

Pela figura anterior verifica-se a enorme capacidade de atendimento ao tráfego proporcionada pelas topologias emaranhadas. Observe que em quase todos os casos só começa a haver bloqueio para tráfego superior a 2,8 erlangs/nó, e mesmo para níveis de tráfego bastante elevados (4,2 erlangs/nó) a probabilidade de bloqueio é inferior a $10 \%$. Além disso, verifica-se a importâneia da escollha do parâmetro $a$ no projeto de redes ópticas, pois dependendo do valor deste, o desempenho entre as topologias pode variar bastante. Observa-se que quanto maior o número de rotas disponibilizadas melhor é o ganho de desempenho, o que no caso faz com que as redes Anel Malha $a=2$ e Anel Malha $a=6$ sejam respectivamente, a pior e a melhor topologia (no que diz respeito a capacidade de atendimento ao tráfego). Note que as topologias com $a=3 \mathrm{c}$ $a=5$ apresentaram desempenho exatamente igual, e pela Tabela 3 verifica-se que elas possuem o mesmo número de rotas, comprovando mais uma vez a dependência do ganho de desempenho com relação ao número de rotas.

\section{PROTEÇÃO AO TRÁFEGO EM REDES ÓPTICAS}

IP sobre WDM (ou a tão chamada Internet Óptica) parece ser uma maneira eficiente e econômica para implementar a futura internet, já que o overhead gerado pelo einpilhamento de protocolos (IP sobre SONET/SDH e/ou ATM) pode ser eliminado. $\mathrm{Na}$ internet óptica de próxina geração, eanais de comunicação direta entre entidades IP podem ser providos pela camada óptica WDM. Dado que a rede IP atual fornece apenas serviços de melhor esforço, o suporte a QoS torna-se um tema crucial de pesquisa, já que futura internet demandará serviços diferenciados. Por exemplo, aplieações como VoIP e vídeo conferência necessitam de um QoS maior do que correio eletrônico.

Como forma de prover QoS, analisamos nesta seção, a alocação de requisições em caminhos com proteção. Com o advento de OADM's e OXC's reconfiguráveis, ações de restauração (como chaveamento de proteção) podem de fato ser realizadas no domínio óptico. O primeiro passo na direção de uma camada óptica com "capacidade de sobrevivência" (survivability) tem sido vislumbrado através do uso de anéis WDM [8].

As simulações foram realizadas para as topologias originadas a partir da duplicação dos nós (seção 3.1), foram adotados anéis com proteção dedicada, sendo os mesmos constituídos por duas fibras em sentidos opostos. Consideramos que um dado percentual do tráfego exige proteção e o restante não necessita. Para atender a demanda que exige proteção, é necessário que haja pelo menos dois caminhos entre os nós origem-destino passando por enlaces disjuntos, easo esta exigência não possa ser atendida a requisição é bloqueada. Já para o caso sem proteção um único caminho é sufieiente.

Para o roteamento do tráfego foi usado o algoritmo DRS, assim, para o caso das requisições com proteção, as rotas são classificadas em ordem crescente de tamanho, e são tomadas as duas menores para se fazer a alocação de comprimento de onda (segundo o algoritmo MS). É importante observar que, assim como nas seções anteriores, continuamos modelando o tráfego por Poisson.

Nas simulações apresentadas a seguir, considerou-se 3 demandas, as quais exigiam que 10,50 e $90 \%$ do tráfego total fosse protegido. É considerado também o caso onde todo o tráfego é sem proteção (seção 3.1).

As Figuras 14 a), b) e c) mostram as simulações realizadas nas redes com $a=1,2$ e 3 , respectivamente. As siglas "S_prot" e "C_prot" na legenda, indicam tráfego sem proteção e com proteção, respeetivamente, e o número entre parênteses representa o percentual de tráfego com proteção. Por exemplo, as curvas S_prot $(10 \%)$ e C_prot(10\%) mostram a probabilidade de bloqueio para as requisições sem e com proteção, quando $10 \%$ da demanda total exige proteção.



Figura 14a. Demandas com diferentes percentuais de tráfego protegido, para a duplicação dos nós com $a=1$. 


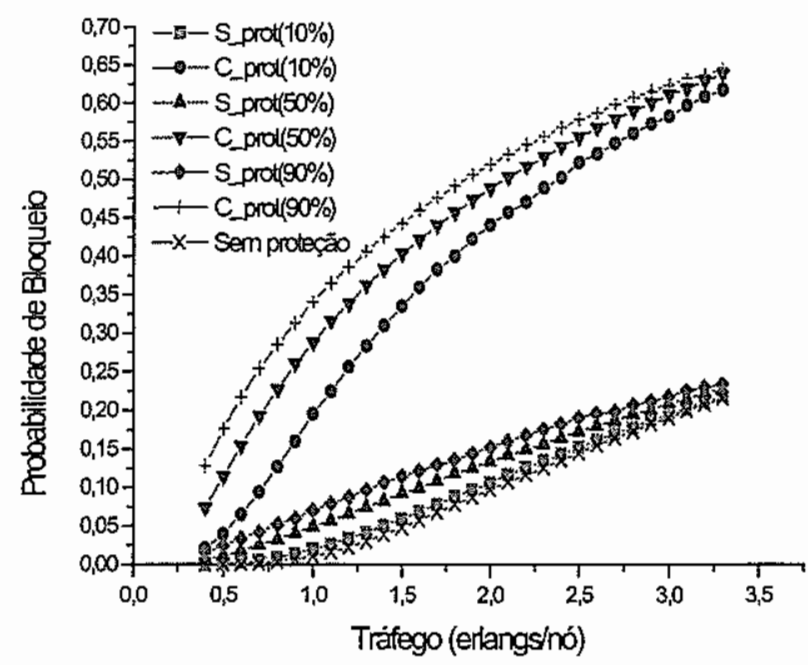

Figura 14b. Demandas com diferentes percentuais de tráfego protegido, para a duplicação dos nós com $a=2$.



Figura 14c. Demandas com diferentes percentuais de tráfego protegido, para a duplicação dos nós com $a=3$.

Observa-se que as requisições com proteção apresentaram uma probabilidade de bloqueio bastante superior às não protegidas. As demandas que possuem um percentual maior de tráfego com proteção têm uma maior probabilidade de bloqueio tanto para as requisições com proteção, quanto para as sem proteção. A demanda com menor probabilidade de bloqueio é quando todo o tráfego é desprotegido (estudado na seção 3.1). De um modo geral, nota-se uma aproximação entre as curvas para níveis de tráfego elevados. Para o caso da topologia com $a=1$, verifica-se que para valores de tráfego superiores a 2,5 erlangs/nó há uma inversão nas curvas das requisições com proteção, ou seja, a demanda com $90 \%$ do tráfego com proteção apresenta agora a menor probabilidade de bloqueio, em seguida a demanda com $50 \%$ e $10 \%$, respectivamente. Diferentemente das demais topologias, no caso com $a=2$, as requisições com proteção já tem valores elevados de bloqueio para tráfego leve (0,4 erlang/nó).

As Figuras 15 a) e 15 b) mostram uma comparação entre as requisições sem proteção e com proteção, respectivamente, para as topologias com $a=1$ e $a=3$, considerando as demandas anteriores.

Para as requisições sem proteção, nas três demandas analisadas a topologia com $a=3$ apresentou desempenho bastante superior a topologia com $a=1$, ○ que esta em conformidade com os resultados obtidos quando todo 0 tráfego não exigia proteção. Já para o caso das requisições com proteção, quando a demanda é predominantemente protegida a situação difere da anterior, pois neste caso, a topologia com $a=1$ possibilita menor bloqueio.



Figura 15a. Requisições sem proteção para as demandas com 10,50 e $90 \%$ do tráfego total protegido.

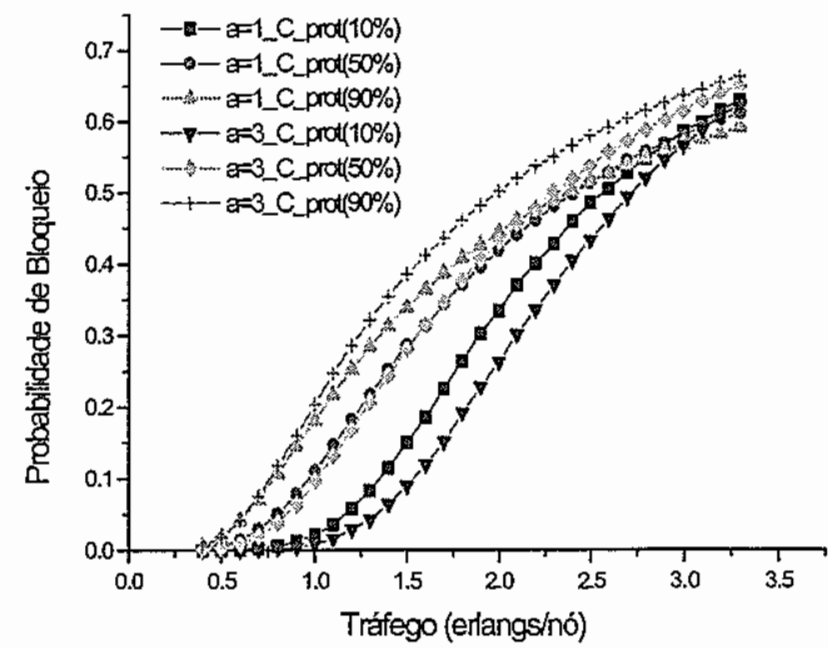

Figura 15b. Requisições com proteção para as demandas com 10,50 e $90 \%$ do tráfego total protegido.

Entretanto, não parece muito viável a utilização deste tipo de topologia para atender à demandas que necessitem que a maior parte do seu tráfego seja protegida, uma vez que a probabilidade de bloqueio atinge valores elevados comprometendo a qualidade de serviço destas redes. Provavelmente topologias mais emaranhadas (redes da seção 3.2.2, por exemplo) possibilitariam melhores resultados, pois em função da capacidade destas, as requisições protegidas poderiam ser melhor atendidas.

Por outro lado, no caso das topologias com duplicação dos nós, pode-se buscar políticas de bloqueio para o tráfego 
tentativo de forma a fazer com que haja una melhoria na capacidade de atendimento das requisições com proteção. Adotamos como política de bloqueio o tamanho máximo das requisições. Considerando a topologia com $a=3$, analisamos três casos distintos, tendo como valores máximos 5, 7 e 10 hops, ou seja, requisições sem proteção maiores que estes limitantes são bloqueadas.

As Figuras 16a) e 16b) mostram estes resultados para as requisições sem e com proteção, respectivamente.

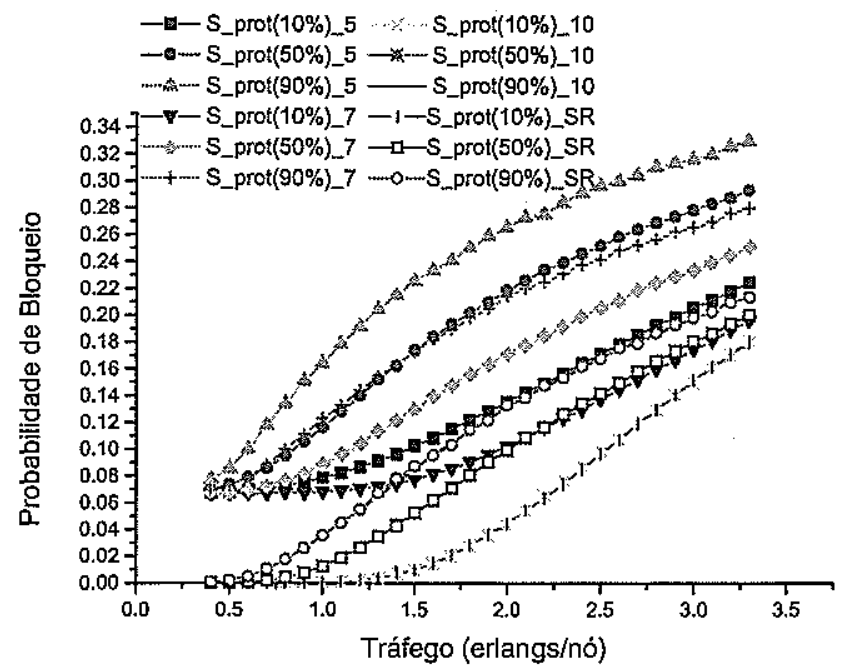

Figura 16a. Probabilidade de bloqueio para as requisições sem proteção, quando estas estão limitadas a 5, 7 e 10 hops, e sem restrição de tamanho (curvas SR).

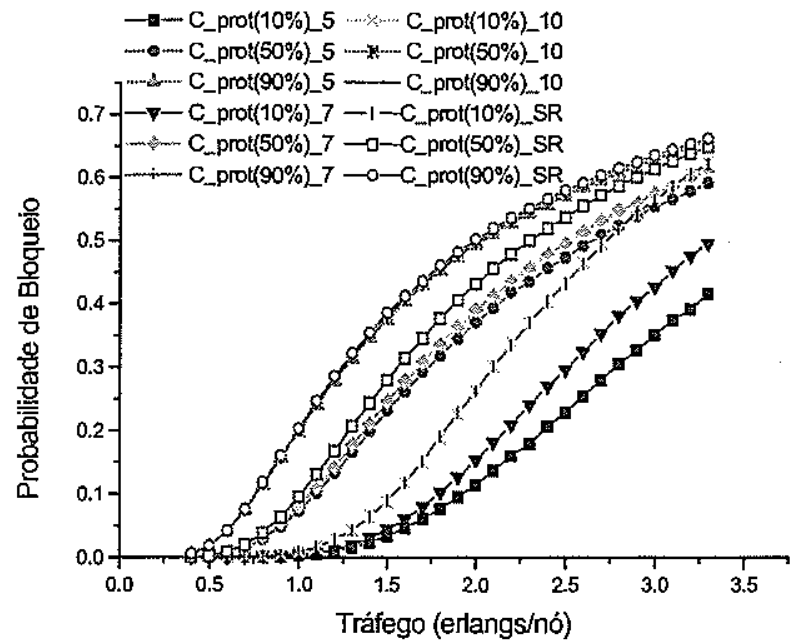

Figura 16b. Probabilidade de bloqueio para o tráfego com proteção, limitando-se o tamanho máximo das requisições sem proteção em 5, 7 e 10 hops e SR (sem restrição).

Claramente observa-se que a adoção de uma boa política de bloqueio proporciona um aumento na capacidade de atendimento ao tráfego protegido (quando este corresponde a um percentual inferior a $50 \%$ do tráfego total), as custas de uma degradação da probabilidade de bloqueio do tráfego tentativo. Nota-se por estas figuras que bloquear requisições maiores que 10 hops não é um bom critério, pois não há nenhum ganho em comparação com o tráfego sem restrição, ou seja, os resultados continuam iguais aos apresentados na Figura 15. Entretanto, quando bloqueia-se requisições maiores que 7 hops obtém-se um.ganho sensível (para a demanda com $10 \%$ do tráfego com proteção), o qual tornase maior ainda quando este limitante passa a ser 5 hops.

A escolla da melhor política de bloqueio provavelmente deve-se basear em questões econômicas, ou seja, nas receitas geradas por ambos tipos de tipos de tráfego. Com certeza as receitas unitárias geradas pelo tráfego protegido são maiores do que as do tráfego tentativo. Considere a Figura 17, a qual mostra a probabilidade de bloqueio para a demanda com $10 \%$ do tráfego total protegido, quando são bloqueadas as requisições sem proteção maiores que 7 hops e para o caso SR.

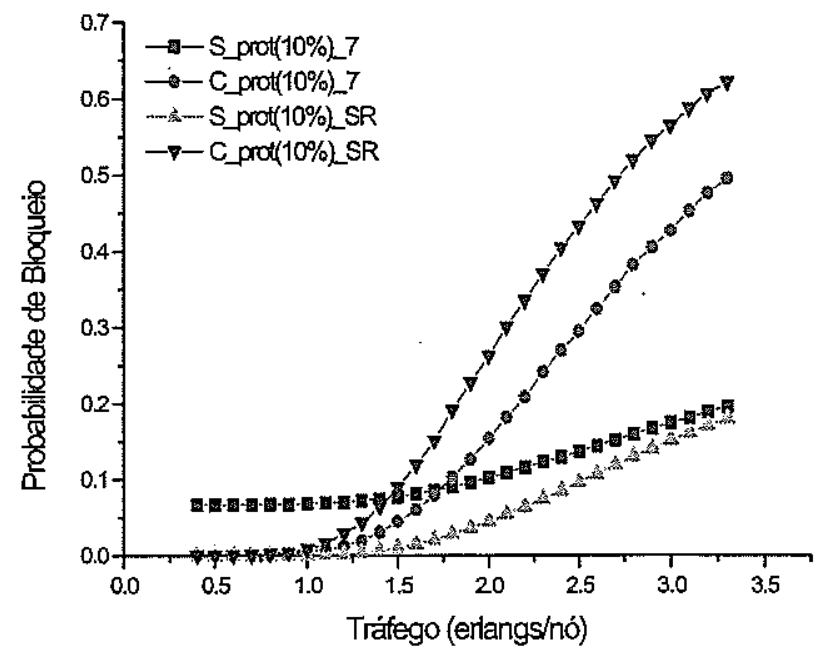

Figura 17. Comparação do ganho obtido quando são bloqueadas requisições sem proteção maiores que 7 hops.

Tomando-se como referência o tráfego de 2 erlangs/nó, a probabilidade de bloqueio para as requisições sem proteção é de 0,044 quando não há restrições com relação ao tamanho máximo da rota, e de 0,102 quando bloqueamos as requisições maiores que 7 hops. Portanto, este aumento de $5,8 \%$ na probabilidade de bloqueio total, corresponde efetivamente a um aumento de $6,44 \%$ no bloqueio do tráfego tentativo (já que este eqüivale a $90 \%$ do tráfego total). Analogamente, para o tráfego protegido obtemos uma queda de $10,9 \%$ na probabilidade bloqueio total, o que corresponde a um aumento de 1,09\% na capacidade de atendimento para este tipo de tráfego.

Desta forma, se as receitas geradas pela demanda que requer proteção, forem pelo menos 6 vezes superiores aquelas geradas pela demanda sem proteção, a escolha desta política de bloqueio torna-se economicamente justificada.

\section{CONCLUSÕES}

As simulações realizadas mostram que para o caso da duplicação do anel de 16 nós, implementar o anel de cordas com $a=3$ proporciona uma maior capacidade de atendimento ao tráfego. É importante salientar que as três alternativas estudadas ( $a=1,2$ e 3 ), apresentam o mesmo custo com relação ao número de OADM's utilizados (32). A utilização do algoritmo de roteamento DRS, mostrou que admitir a rota mais longa entre as opções de alocação só é vantajoso para níveis de tráfego suficientemente baixos. Acima de um certo nível crítico, é melhor proibir a rota mais longa. 
Nas redes constituídas por OADM's e OXC's, vimos que a utilização destes últimos proporciona um enorme aumento no número de alternativas de roteamento em comparação com as topologias anulares, entretanto, este fato não provocou um aumento proporcional na capacidade destas redes, já que o melhor desempenho (Anel Cordas $a=4(8$ OXC's)) foi praticamente o mesmo do caso da duplicação dos nós com $a=3$, o qual só disponibiliza 4 alternativas de roteamento. Verificamos também que modificando 0 algoritmo de alocação conjunta de rota e comprimento de onda (JRW), para que o mesmo passe a escolher a melhor rota (segundo o MS) somente entre as menores disponíveis, resultou um em algoritmo que apresentou o melhor desempenho (JRW_SP), e vimos o quanto este desempenho é degradado se forem alocadas rotas maiores que a menor disponível.

No caso da rede "Anel Malha" que é constituída somente por OXC's, verificamos a imensa capacidade disponibilizada por elas, e também a importância na escolha do parâmetro $a$.

A análise das demandas com exigências de QoS em topologias formadas pela duplicação dos nós, mostrou que estas redes não oferecem muitas condições para dar suporte a este tipo de tráfego quando a demanda é predominantemente com proteção. Todavia, se apenas um pequeno percentual deste tráfego exigir proteção, a adoção de uma boa política de bloqueio pode ser economicamente atrativa.

As métricas obtidas para implementar o MS no anel, foram de grande valia, já que evitaram que fossem feitas contagens exaustivas de todos os caminhos afetados por cada alocação viável, fato este que não pode ser evitado nas redes com OXC's, pois nestas topologias há um emaranhado de caminhos ("mesh networks"), perdendo-se o sentido falar em imserção assimétrica em buracos. Isto provocou um agravante nas simulações, já que o tempo de simulação aumentou bastante. Desta forma, seria bastante interessante a obtenção de mćtricas para a implementação do MS em topologias genéricas.

Outro tema a ser investigado, diz respeito ao melhoramento do algoritmo MS, já que ele atribui o mesmo custo a todos os decréscimos de capacidade de rota de $k$ para $(k-1)$ canais, independentemente do valor de $k$. Entretanto, as rotas cuja capacidade passar de um para zero ficarão bloqueadas imediatamente após a alocação que causar essa perda, ao passo que as outras (com $k>1$ ) apenas ficarão mais vulneráveis a futuros bloqueios. Assim sendo, parece razoável esperar que 0 algoritmo tenha seu desempenho melhorado atribuindo-se custos (à perda de capacidade) que sejam função decrescente de $k$.

\section{REFERÊNCIAS}

[1] P.E. Green, Jr., "Optical Networking Update", IEEE Journal on Selected Areas in Communications, vol. 14, pp. 764-779, jun. 1996.

[2] Chlamtac, A. Ganz e G. Karmi, "Lightpath Communications: an Approach to High-Bandwidth Optical WAN's", IEEE Transactions on Communications, vol. 40, pp. 1171-1182, jul. 1992.

[3] H. Zang, J.P. Jue e B. Mukherjee, "A Review of Routing and Wavelength Assignment Approaches for Wavelength-Routed Optical WDM Networks", Optical Networks, vol. 1, pp. 4760 , jan. 2000.

[4] S.Subramaniam e R. Barry, "Wavelength Assignment in Fixed Routing WDM Networks", IEEE Int'l Conf. Comm, pp. 406410, jun. 1997.

[5] H. Waldman, D.R. Campelo e R. Camelo, "Dynamic Priority Strategies for Wavelength Assignment in WDM Rings", 2000 IEEE Global Telecommtnications Conference (Globecom'00), Conference Record, pp. 1288-1292, San Francisco, U.S.A, 27 de novembro - 01 de dezembro de 2000.

[6] D.R. Campelo, R. Camelo e H. Waldman, "Estratégias de Ampliação da Capacidade de Anéis Ópticos com Bloqueio", CD-ROM XVIII Simpósio Brasileiro de Telecomunicações, artigo 5150118, Gramado, RS, 03-06 setembro, 2000.

[7] R. Camelo, "Alocação de Rota e Comprimento de Onda ein Anéis WDM", Tese de Mestrado, FEEC/UNICAMP, março/2001.

[8] P. Bonenfant, "Protection and Restoration in Optical Networks", Proc. Of OFC' 99, San Diego, USA, Tutorial Sessions, pp. 199-214, Feb. 1999.

[9] R. Ramaswami and K. N. Siravajan, "Routing and Wavelength Assignment in All-Optical Networks," IEEE/ACM Transactions on Networking, vol. 3, no. 5, pp. 489-500, Oct. 1995.

José Renato de Paula Naves, 25, graduou-se Engenheiro Eletricista pela Universidade Estadual Paulista (UNESP) campus de Ilha Solteira (1999), e está concluindo o mestrado no departamento de comunicações (DECOM) da UNICAMP.

Helio Waldman, 57, graduou-se Engenheiro de Eletrônica pelo ITA (1966), e M.Sc. e Ph.D. pela Univ. de Stanford, USA (1968 e 1972, respectivamente). Após dois anos na COPPE/UFRJ como Professor Adjunto, juntou-se à Universidade Estadual de Campinas (UNICAMP), onde é Professor Titular desde 1980, quando foi nomeado Diretor Associado da Faculdade de Engenharia de Campinas. Em 1982, foi nomeado Diretor da mesma Faculdade, cargo que ocupou até 1986. De 1986 a 1990, foi Pró-Reitor de Pesquisa da UNICAMP. Foi Presidente da Sociedade Brasileira de Telecomunicações de 88 a 90 e Editor da Revista da Sociedade Brasileira de Telecomunicações de 92 a 96. É autor ou co-autor de três livros, doze artigos em periódicos estrangeiros, e dezenas de artigos em Anais de Congressos nacionais e internacionais. 